\title{
THE INCENTIVE EFFEGTS OF TOURNAMENTS REVISITED: EVIDENCE FROM THE EUROPEAN PGA TOUR
}

\author{
RONALD G. EHRFNBERG and MICHAEL L. BOGNANNO*
}

\begin{abstract}
This analysis of data from the 1987 European Men's Professimal Golf Association (PGA) Tour strongly supports the hypothesis that the level and structure of prizes in PGA tournaments influence playets' performance. Specifically, players' performance appears to vary positjvely with both the total money prizes awarted in a tournament and the marginal return ro effort in the final round of play (a value that varies among players largely depending on how the prizc money is allocated among finishers of different ranks). The authors suggest that these results, together with the similar results of their sarlier study of the 1984 L'S. Men's PGA Tour, may have implications for the design of compensation systems for certain groups of workers. such as corporate executives, college professors, and salespeople.
\end{abstract}

$\mathrm{E}$ Conomists have recently devoted considerable attention to models of tournaments, or situations in which an individual's payment depends only on his output or rank relative to other competitors.' Such models are of more than academic interest, as they may well describe the compensation structures applicable not only to professional sports tournaments but to many corporate executives (who can

* Ranald Ehrexberg is Irving M. Ives Professor of Industrial and Iabor Relations and Economics at Cornell University and Research Associatc at. the National Burean of Economic Research, and Michad Bognanno is a Ph.D. candidate in Labor F.conomics at Cornell University. l"his paper is based on work supported by the National Science Foundation under Grant No. SES-8719592, and the authors thank the Foundation for its support. The data set uscd in the paper will be archived at the Intet-Liniversity Consortium for Political and Social Rescarch (P.O. Box 1248, Ann Arbxr, Michigan 48106) as of Jantary 1, 1991.

See Lazear and Rusen (1981), Carmichae) (1983), Green and Stokey (1983), Malconson (1984). Nalebuff and Stiglitz (1984), O'Keefe, Viscusi, and Zeckhauser (1984), Rosen (1986), and McLaughlin (1988) for discussichss of tourtament theory. be thought of as compering with colleagues for promotions), young college professors (who may be thought of as competing with colleagues for teinure), and sales people (whose bonuses often depend on their relative outputs).

Academic interest in tournament models derives from the incentive effects that such compensation striclures are thoughi. to have. In particular, under certain sets of assumptions tournaments are thought to give participants an incentive to provide optimal levels of effort. ${ }^{2}$

Very few attempts have becn riade, however, to test either if tournaments actually elicit desired effort responses or if executive compensation is generated by at tournament-type reward strunture." Thic

\footnotetext{
4 These assumptions relate wo the axssts of monitoring effort, asymmetric; inforsation, and the nature of random shocks to output/productivity.

${ }^{3}$ Buli, Schotter, and Weigett (1987) is an experimental study that used paid undergratuate sudent volunteers as subjests to to:s whether tournament's clicit desired cffort rcsponses. O'Reilly et al. (1988) is
} 
lack of studies that use corporate data is undoubtedly due to the difficulty of measuring both individual cxecutives' effort levels and the incentive structures they face.

In previous research we have examined data from professional golf tournaments in the United States to test whether tournaments do have the postulated incentive effects (Ehrenberg and Bognanno 1988). Our focus was on golf tournaments because data were available for them on the incentives players face (the prize distribution in each toumament) and measures of each individual's output (the player's score). In addition, data were available to control for factors other than the prize structure that should affect a player's score in a tournament, such as the player's "quality," the "quality" of his opponents, the difficulty of the tournament's course, and the weather conditions during the tournament. Thus, our analysis could isolate the effect of the prize structure on player performance. In the main, the results presented in that paper indicated that tournaments' prize structures $d o$ affect players' performance.

In the present paper we seek to test the robustness of our previous findings by performing a similar analysis using data from the 1987 European Men's Professional Golf Association (PGA) Tour.

\section{Analytical Framework}

Our econometric work is based on implications derived from simple twocontestant models that capture the essence of the incentive problem. ${ }^{4}$ If one wishes, one can view the two-person tournament as a situation in which a contestant competes against "the rest of the field."

Each individual's score in a tournament is assumed to depend on his effort concentration level, a pure random or

\footnotetext{
a resent attempt to tosi whether cxccutive compensation corrsponds to a tournament structure.

4 Details of thesc models cax be found in Lazear and Rosen (1981) and Ehrenberg and Bognanno (1988). Gencralizations to the n-comtestant case are found in (Green and Stokey (1983) and elsewhere.
}

luck component, and tournament-specific factors such as the difficulty of the course and the adversity of weather conditions. For simplicity, the last two factors are assumed to affect all players in a tournament equally. A key assumption in the model is that players choose their effory concentration levels.

Of course, one may argue that treating the effort/concentration levels of professional golfers as choice variables does not make sense because professionals always play as hard as they can. ${ }^{5}$ What this criticism ignores, however, is how difficult it is even for professionals to maintain their concentration levels over tournaments that typically last four days per week and that involve four to five hours of physical effort per day. Furthermore, playing on the PGA European Tour involves weekly international travel and living out of hotel rooms. At the very least, one might expect fatigue to set in during the latter days of each tournament and players' ability to maintain their concentration to diminish at these times. To capture this effect, we assume that each individual faces a "cost of effort/concentration" function and that the marginal cost of effort is positive and increases as effort increases.

Given a prize differential for winning, each player is assumed to choose his effort level to maximize his expected utility. If, furthermore, we posit that each player assumes his opponent is similarly choosing his optimal strategy, a solution can be found for each player's optimal effort/ concentration level and thus his score. In particular,

$$
\begin{aligned}
& q_{j i}= \\
& u_{j i}\left(\left(w_{1 i}-w_{2 i}\right), A_{j a} A_{j i}\right)+\epsilon_{j i}+\delta_{j *}
\end{aligned}
$$

Here $q_{j i}$ is individual $j$ s score in tournament $i, w_{1 i}-w_{2 i}$ is the prize differential for winning, $A_{j o}, A_{j c}$ are measures of the player's own ability and his competitor's ability respectively, $\delta_{i}$ reflects the tourna-

\footnotetext{
"In fact, the U.S. PGA Tour's 1984 Player's Handbook (1984) states that "in making a commitmeut to play in a PGA Tour cosponsorcd or approved event, a player obligates hivusclf to exercise his maximum golf skill and to play ill a professional manner" (p. 58).
} 
ment-specific factors, and $\epsilon_{j i}$ is a random error term. Equation (1) states that a player's score in a tournament depends on the prize differential for winning, how "good" the player is relative to his opponent, tournament-specific factors such as the weather and course difficulty, and a random error term. One crucial implication of this model is that higher prize differentials for winning should lead players to exert more effort/concentration and thus should result in better (that is, lower) scores.

\section{The 1987 Men's Europear Professional Golf Tour}

The typical golf tournament has four rounds. Half the field is "cut" at the end of the second round, two additional rounds are played, and then prizes are awarded on the basis of the players' ranks after the final round. Of the 29 tournaments on the 1987 European Men's Professional Golf Association lour, 27 were of this type, and data from 23 of these are used in our analysis. ${ }^{6}$

Across these tournaments the structure of the allocation of prize money by rank was virtually identical, although the level of prize money varied across tournaments. ${ }^{7}$ Figure 1 summarizes this structure. An important effect of the prize structure is that it gave a much higher marginal return for improving one's performance by one rank (or not seeing one's perforruance decline by one rank) to players who

\footnotetext{
${ }^{6}$ See Pro-Golf '88: The Official PGA European Tour Gnide (1988). The six rournaments not included in the sample wert two match-play cournaments that had different formats and much smaller fields (Epson Grand Prix of Furope Match-Play, Dunhill Cup Nations Tournament), two tournaments that were interrupted after three rounds because of the weacher (Volvo Belgian Open, Porcuguese Open), a tournament open only to golfers aged 50 and older (Senior British Open), and the Open Golf Championship, in which the eligibility criteria and the prize structure differed from those in the other tournamerts. A listing of the 23 tournaments included in the sample and the total prize money awarded in each appears in Appendix Table $\mathrm{Al}$.

${ }^{7}$ See Pro-Golf '88: The Official PCA European Tour Givide (1988).
}

were close to the leaders after three rounds than to players who were far from the leaders. For example, the narginal prize received for finishing second instead of third was approximately 5 percent of the total tournament prize money, whereas the marginal price received for linishing nineteenth instead of twentieth was less than 0.1 percent of the total tournament. prize money. $^{8}$

This structure of prizes, coupled with variations in the level of prizes across tournaments, suggests two types of tests of the theory sketched in the preceding section. First, since the structure of prizes is constant across toumaments, the prize differential for "winning" depends only on the level of total prize money. Thus, one can focus on a tournament as a whole and ask, other things equal, if higher total prize money leads to lower scores for the tournament as a whole. Secorid, one can focus only on the last round of a tournament and ask if a player's performance in the last round depends, other things equal, on the marginal return to effort. The marginal return to effort will depend, in turn, on the total prize money in the tournament, the player's rank after the third round, and how many players are tightly bunched around him after three rounds. The results of both of these types of analysis are reported iti the next section.

Before turning to the empirical results, however, we must discuss one institutional complication. Not every pro golfer who wanted to enter any given European PGA tournament in 1987 could do so. Rather, it system of exemptions and priorities existed. At the risk of simplifying a very complex system, we would describe it as follows: ${ }^{9}$

\footnotetext{
* Appendix Table A'2 presents data on the mean level and share of prize money won expost for players at various ranks in thesc tourniments. Because of ties in some tournaments for some ranks, the exprost share of the prize money won ar each rank is net iderticall. across tourdirmerits.

${ }^{9}$ See Pro Golf '88: the Official PCA Europin' Tomt Cuide (1988), pp. 55-57. In addition to the discinctions noted in the text. members of the Europenn Ryaler Cup 'Team fell in group (ii), past winncrs of a
} 


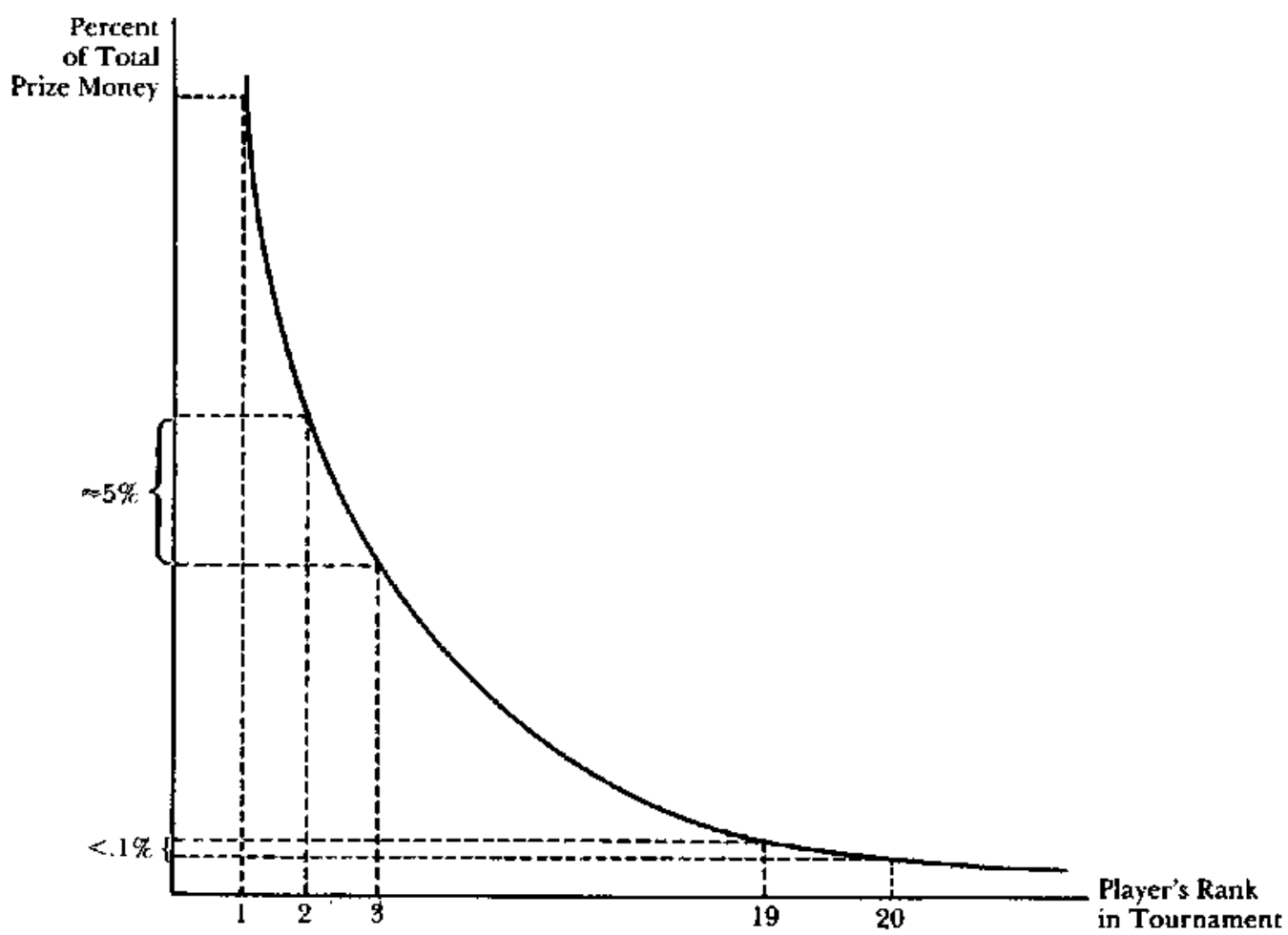

Figure 1. Share of Tatal Prize Money Going to Players of Different Ranks: Sample from 1987 Men's European PGA Tournament.

(i) Any golfer who had won any "major" tournament after 1977 or any European PGA Tour tournament in 1986 could exter any tournament he wanted in both 1987 and 1988.

(ii) Any golfer who failed to qualify under (i) and had won a specified major tournament in 1977 or any European PGA Tour tournament in 1985 could enter any tournament he wanted in 1987 but had no promise of entry for tournaments in 1988.

(iii) If all positions in a 1987 tournament were not filled by individuals from categories (i) and (ii), any golfer who was among the top 40 career money winners as of 1986 or was among the top 128 money winners on the 1986 European PGA Tour could enter the tournament.

(iv) Any remaining vacancies in a tour-

specific tournanent received an exemption for that specific tournament, and each rournament sponsor was allowed to invice a specified number of players to participare in this or her tournament. nament were filled with players who met other criteria (for example, lower-ranked players on the 1986 tour, and leaders from the European PGA Tour Qualifying School).

As we shall show, this system of exemptions and priorities helps to explain which players entered which 1987 PGA Tour tournaments. This consideration is important because analyses that use data on the scores of entrants to tournaments may be subject to potential selectivity biases. In addition, individuals in categories (ii), (iii), and (iv) had to be very concerned about their total tour earnings in 1987, for unless they won a PGA Tour tournament during the year, they had to finish in the top 128 money winners during the year in order to be assured of virtual automatic entry (if they desired) to European PGA Tour tournaments in 1988 (that is, to be in category (iii) in 1988). In contrast, no matter what individuals in category (i) accomplished during the 1987 tour, they 
were assured the option of entry into any European PGA Tour tournament that they wanted to enter in 1988.

Suppose that the latter (rategory (i)) group, whom we refer to henceforth as the exempt players, exhibited effort levels that werc sensitive to the level and structure of prizes in a tournament. Because the former (category (ii), (iii), and (iv)) group, whom we henceforth refer to as the nonexempt players, had to worry about qualifying for the next year's tour, the level and structure of prize money in a tournament may not be an accurate indicator of their marginal financjal return to effort. Rather, one would need to know also how an increase in effort for one of them increased both the probability that he would be classified as an exempt player in 1988 and his expected future earnings if he was so classified. As such, even if the excmpl and nonexempt players' marginal responses to financial returns were equal, one might intuitively expect nonexempt players' effort levels, and hence scores, to be less sensitive than those of exempt players to tournamentspecific prize variables. ${ }^{10}$

\section{Empirical Analysis}

Our empitical analysis proceeds in two stages: first we estimate final score equations for players on the 1987 European Men's PGA Tour; then we estimate final round score equations.

\section{Final Score Equations}

Pro Golf '88: The Official PGA European 7our Guide (1988) provides data for each 1987 Men's PGA European Tournament on the score by round, final rank, and prize money won for all players who entered and made the cut." ' Data on each player's scoring average on all rounds

${ }^{10}$ 'The appcridix to Ehreuberg and Bognamno (1988) presents a simple omitted variable model that indicatcs the precise conditions under which this expectation is correct.

1 The restriction to players who entered and made the cut leads to poteritial selecrivity problems, and we discuss this issue below. (See notc 16.) during the year, a measure of his "ability," are available only for the top 1,30 money winners during the year; consequently, the analysis reported below is restricted to these individuals. ${ }^{12}$

Equations were estimated (pooling the data across individuals and tournaments) of the form

$$
\begin{aligned}
s_{j i}= & a_{0}+a_{1} \mathrm{TPRIZE}_{i}+a_{\mathrm{L}} \mathrm{MAJ}_{i} \\
& +a_{9} x_{i}+a_{4} y_{j}+a_{5} z_{i}+v_{j i}
\end{aligned}
$$

Here, $s_{j i}$ is the final score of individual $j$ in tournament $i$, 'TRIZF ${ }_{i}$ is the total prize money awarded in the tournament, $\mathrm{MAJ}_{i}$ takes on the value of one if tournament $i$ is a major tournament and zero otherwise, $x_{i}$ is a vector of variables to conirol for the difficulty of the tournament course, $y_{j}$ is a vector of proxies for player $j$ 's ability, $z_{i}$ is a vector of variables to control for the quality of other players in the tournament, and $v_{j i}$ is a random exror term. ${ }^{1 s}$ If the theory of tournaments is correct, higher prizes should lead to lower scores, and estimates of $a_{1}$ should therefore be negaive. Similarly, since winning a major tournament typically provides a golfer with endorsement opportunities and also provides him with guaranteed entry to all tournaments for a number of years, estimates of $a_{2}$ should also be negative. ${ }^{11}$

The controls for the difficulty of the course are PAR, the par for the tourna-

\footnotetext{
${ }^{2}$ As a result, vircually no individuals from category (iv) are included in the sample.

is Our earlier study of L'.S. golf tournaments included a measure of the weather conditions during cach tournament as an explanatory variable. Lufortunately, such a measure could not be constructed for this paper, as detailed descriptions of the wearher on exch day of each tournament were not readily available to $\mathrm{us}$. As long as weather conditions are uncorrelared with the other explanarory variables in the model, the omission of that factor will reduce the model's explanatory power but not lead a biased estimates of any of the other coefficients.

${ }^{14}$ The five "major" tournaments are rhe PGA Championship, the Open Championship, the TPC, the European Open, and the European Mastens. The TPC was nut played in 1987 and, as noted above, whe Open Championship was not included in our sartıple.

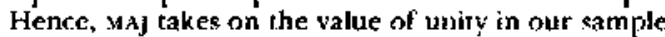
for the PGA, European Operr, and European Masters tourtatisents.
} 
ment course; and YARDS, the total course yardage. Player ability is proxied by SAVE, his scoring average on all rounds played during the 1987 European tour; and SPARR, his average number of strokes per round worse $(+)$ or better $(-)$ than par for all rounds he played during the 1987 European tour. Finally, the quality of the other players in the field is proxied by MSAVE and MSPARR, the mean values of SAVE and SPARR respectively, for all players who finished in the tournament, and by TOP2n, the number of the top 20 money winners on the 1987 Men's PGA European Tour who finished in the tournament.

Estimates of equation (2) are reported in Table 1 and descriptive statistics for the variables used are found in Table 2. More difficult courses, as measured by higher pars or longer yardage, are associated with high scores. Similarly, the better the player, as measured by lower values of either SAVE or SPARR, the lower the player's score will be. Most striking, the coefficients of MAJ in columns (1) and (2) of Table 1 imply that players' scores, ceteris paribus, average more than one scroke lower in the major tournaments. Similarly, the coefficient of TPRIZE is negative as anticipated. TPRIZE is measured in thousands of pounds; hence, the results in columns (1) and (2) imply that increasing the total prize money by $£ 60,000$ would be associated with each player scoring, on average, about three strokes less during a tournament. During 1987, the exchange rate averaged about 6 pounds per dollar, so this change in prize money is roughly equivalent to $\$ 100,000,{ }^{15}$ In our earlier paper, we found that an increase in prize money of this magnitude would cause the score of the typical golfer on the 1984 U.S. PGA Men's Tour to fall (improve) by about 1.1 strokes during a tournament (Ehrenberg and Bognanno 1988, 'Table 1). Apparently, golfers' performances are more sensitive to prize levels on the Furopean tour than on the U.S. tour.

Columns (3) and (4) of Table 1 present

\footnotetext{
${ }^{15}$ Economix Report of the President (1988), Table B- 108 .
}

estimates of specifications in which TPRIZE and $\mathrm{MAJ}$ are interacted with a variable that indicates whether, as of the start of the 1987 tour, the player has already automatically qualified to enter tournaments on the next year's (1988) Men's European PGA Tour (EXEM). The negative coefficient of the interaction term with TPRIZE suggests, as noted above, either that exempt players' effort levels are more responsive to financial variables, or that the nonexempt players' TPRIZE coefficient is biased toward zero because their marginal return to effort also depends both upon how doing well in a tournament increases their probability of being classified as exempt in the next year and upon their expected increase in the present value of future income if so classified. ${ }^{16}$

Althougl not central to our discussion here, it is also of interest to know which factors influence players' decisions to enter tournaments. Columns (1) and (2) of Table 3 present estimates of probit probability of entry equations. The probability is specified to be a function of a player's total career earnings prior to 1987 (PRCASt), his age (AGE), the order of the tournament in the year and its square (TCODE, 'TCODF2)

\footnotetext{
16 The results in Table 1 may be subject to two types of selection bias because the sample is restricted to the subser of players who both entercd and made the cut in earh toumament. Consequently, we may confound the effect of the total prize variable on players' final scores with its effect on their probability of entering and making the cut in a tourmament. Controlling for this possible problem requires the use of information on the players who entered each tournament and Failed to make the cut: fortunately, such information is found in Pro Golf ' 88 : The Official PGA Europenn Tour Guide (1988).

To model separately the decision to enter a tournament and the probability of making the cut and then to estimate a bivariate selection model is a difficult task. Instead, we approximated this process and estimated a univariate probit probabilicy of entering and making the cut equation. Following the approach initially suggested by James Heckman (1979), we then used estimates from this equation to compute an estimate of the inverse Mils tatio for each individual and entered the latter as an additional explanatory variable in equation (2) to control for selectivity bias. When these "augnented" equations were estimated, the selectivity bias adjustment procedure was seen to have virtually no effect on the TPRIZE cuefficients.
} 
Table 1. Final Score Equations for the 1987 PGA Men's European Tour; Data Pooled Across Tournaments and Players.

(Absolute Value t-Statistics in Parentheses)

\begin{tabular}{|c|c|c|c|c|}
\hline Variable & (I) & (2) & (3) & (4) \\
\hline Intercept & $-1,208.233 \quad(6.2)$ & $21.442(1.0)$ & $-1,201.470 \quad(6.2)$ & 21.764 \\
\hline TPRIZE & $-.050(10.6)$ & $-.050(11.1)$ & $-.049(10.4\}$ & $-.050(11.0)$ \\
\hline TPRIZE*EXEM & & & $-.004(1.7)$ & $-.004 \quad(1.5)$ \\
\hline MA] & -1.177 & $-1.307 \quad(2.2)$ & $-1.287 \quad(2.0)$ & $\therefore 1.400$ \\
\hline MA]*FXEM & & & .451 & .377 \\
\hline PAR & $2.411 \quad(6.0)$ & 3.216 & 2.412 & 3.214 \\
\hline YARDS & $.004 \quad(2.4)$ & (1.8) & $.003 \quad\langle 2.4\}$ & .003 \\
\hline SAVE & $3.026(16.9)$ & & $2.903(15.1)$ & \\
\hline MSAVE & $14.892 \quad(5.4)$ & & $14.921 \quad(5.4)$ & \\
\hline SPARR & & $8.042(17.2)$ & & $2.935(15.3)$ \\
\hline MSPARR & & $18.511 \quad(6.9)$ & & $18.546 \quad(6.9)$ \\
\hline TOP20 & $1.309(10.8)$ & 1.495 (11.7) & 1.315 (10.3) & $1.500(11.7)$ \\
\hline$\tilde{\mathbf{R}}^{2}$ & .434 & .444 & .438 & .445 \\
\hline $\mathbf{n}$ & 1,886 & 1,386 & 1,386 & 1,386 \\
\hline
\end{tabular}

TPRIZE: total tournament prize money, in hundreds of British pounds.

EXEM: 1 = player has automatically qualificd to enter tournaments on the 1988 Men's European PGA tour; $\theta=$ not automatically qualified.

MAJ: $1=$ PGA, European Masters, or Eurojean Open Tournament; $0=$ orher.

PAR: par for the tournament course.

YARDS: course yardage.

SAVE: player's scoring average on all rounds played during the 1987 European tour.

MSAVE: mean value of SAVE for all players who finished the tournament.

SPARR: player's average number of strokes worse $(+)$ or better $(-)$ than par for all rounds played during the 1987 European tour.

MSPAR: mean value of SPARR for all players who finished the tournament.

Top20: number of the top 20 moncy winners on the 1987 PGA Men's European tour who finished the tournament.

Source: Authors' calculations from data in Pro-Golf '88: Volvo Tour, The Official PGA European Tour Griude (1988).

to allow for seasonal patterns, the total tournament prize money (TPRIZ.E), whether the tournament is a major tournament

Table 2. Descriptive Statistics for the Variables Used in the Final Score Equations.

\begin{tabular}{|c|c|c|c|c|}
\hline Variable & Mean & $\begin{array}{l}\text { Stan- } \\
\text { dord } \\
\text { Devia- } \\
\text { tion }\end{array}$ & $\begin{array}{l}\text { Mini- } \\
\text { matum } \\
\text { Voluse }\end{array}$ & $\begin{array}{l}\text { Maxi- } \\
\text { mum } \\
\text { Value }\end{array}$ \\
\hline ISCORE & 286.57 & 8.66 & 259.00 & 319.00 \\
\hline TPRIZE & 199.32 & 56.45 & 98.17 & 399.09 \\
\hline EXEM & 0.19 & 0.39 & 0.00 & 1.00 \\
\hline MAJ & 0.13 & 0.33 & 0.00 & 1.00 \\
\hline PAR & 71.83 & 0.68 & 69.00 & 73.00 \\
\hline YARDS & $6,837.58$ & 210.58 & $6,198.00$ & $7,362.00$ \\
\hline SAVE & 72.02 & 0.97 & 69.19 & 74.63 \\
\hline MSAVE & 72.03 & 0.17 & 71.61 & 72.39 \\
\hline SPARR & 0.81 & 0.98 & -2.58 & 2.98 \\
\hline MSPARR & 0.31 & 0.18 & -0.11 & 0.60 \\
\hline Tolmo & 12.63 & 3.59 & 5.00 & 20.00 \\
\hline
\end{tabular}

TSCORE: player's toral number of strokes over the four rounds of the tournarnent.

All other variables are defined in Table $\mathbf{I}$.
(MAJ), and the player's quality (SAVE in column (1), SPARR in column (2)). Coefficient estimates are permitted to vary between exempt and nonexempt players, and an " $A$ " before a variable's name indicates that the coefficient is for exempt players, whereas a " $B$ " indicates that it is for nonexempt players.

Both exempt and nonexempt players are seen to be more likely to enter major tournaments and tournaments in which the total prize money is bigher. ${ }^{17}$ An income effect on labor supply is evident for exempt players since, ceteris paribus, the greater an exempt player's lifetime earn-

\footnotetext{
17 Recall that only the top 130 mnev winners on the tour are includerl in our sample. Thus, if a decrease in a variable reduces the likelihosd of entry for both exempt and nonexempt players in a tournament, an implication is that the decrease also permits mure players who are not among the top 130 money winncrs to enter the tournament.
} 
Table 3. 1987 PGA Men's European Tour: Probit Probability of Entry. (Absolute Value t-Statistics in Parentheses)

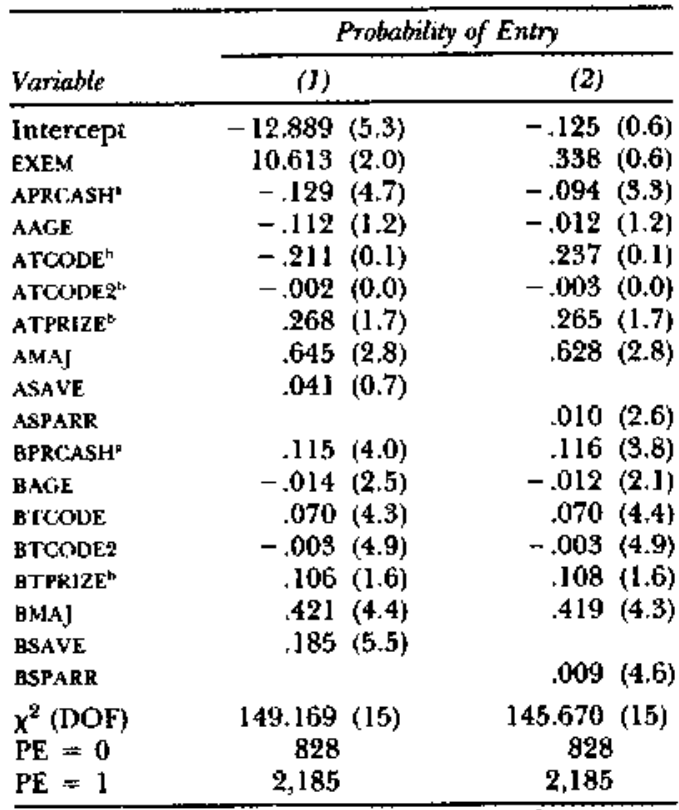

a Coefficient has been multiplied by $10^{5}$.

$\checkmark$ Coefficient has been multiplied by $10^{2}$.

An " $A$ " before a variable name indicates the variable's coefficient for exempt players, and a " $\mathrm{p}$ " before a variable's name indicates its coefficient for nonexempt players.

PRCASH: total career earnings prior to 1987.

AGE: age.

TCODE: tournament code, in chronological order (equals $1 \mathrm{for}$ the first tournament).

TCODE2: tournament code squared.

PE: $1=$ entered the tournament; $0=$ did not enter the coutnament.

See Table 1 for all other variable definitions.

ings, the lower his probability of entering a tournament. In contrast, the greater the lifetime earnings of nonexempt players, the more likely they will enter tournaments. Older nonexempt players enter fewer tournaments. Finally, better players, as measured by lower values of SPARR, enter fewer tournaments.

\section{Final Round Score Equations}

Consider a golfer playing in two tournaments with the same total prize money. Suppose he scores a 72 on each of the first three days of both tournaments but, because of random factors that influence his opponents' performance, he finds himself in third place in the first tournament but in twentieth place in the second tournament. Given the structure of PGA tournament prizes (Figure 1), he faces a greater marginal return to efforvconcentration in the first tournament, should exert more effort/concentration there, and, on average, should have a lower final round score in that tournament. Put another way, we should expect to observe, ceteris paribus, a positive correlation between a player's rank after the third round of tournaments and his final round scores.

The results of an initial test of this hypothesis are shown in Table 4 . Here, we have estimated final round score equations, using data pooled across individuals and tournaments. A player's score on the final round of a tournament is specified to be a function of his scores on the first three days of the tournament (SCOREl, SCORE2, SCORE3), his rank after the third round (RANK3RD), and the total tournament prize money (TPRIZE). A player's scores on the first three days, which are probably the best predictor of how well he is currently playing, should be positively associated with his score on the final day. Given his scores on the first three days, higher rank (poorer relative position) after the third round should lead to higher final round scores, and higher total prize money should lead to lower final round scores. The total prize level should matter because a higher average prize level leads to larger prize differences between players of different ranks.

A player's scores on the first three days of a tournament are not exogenous, but rather depend (from equation (1)) on the prize differential for winning, measures of his ability and his opponents' ability, and tournament-specific factors such as course difficulty. Similarly, neither is a player's rank after the third round exogenous. It depends on his scores and his opponents' scores on the first three days-both of which depend, in turn, on the factors described above. As such, we treat SCORE1, SCORE2, SCORE3, and RANK3RD as endoge- 
Table 4. Final Round Score Equations for the 1987 PCiA Mcn's European Tour: thata P'ooled Across Tournaments and Players, ${ }^{2}$

(Absolute Value t-Statistics in Parentheses)

\begin{tabular}{|c|c|c|c|}
\hline Variable & $\begin{array}{l}\text { All Players } \\
\text { (I) }\end{array}$ & $\begin{array}{c}\text { Nonexempt Players } \\
\text { (2) }\end{array}$ & $\begin{array}{c}\text { Exempt Plowers } \\
\text { (3) }\end{array}$ \\
\hline $\begin{array}{l}\text { Constant } \\
\text { sCOREI }\end{array}$ & $\begin{array}{r}23.889(3.2) \\
.330(1.5)\end{array}$ & $\begin{array}{r}24.894(3.1) \\
.271(1.1)\end{array}$ & $28.508(1.7)$ \\
\hline SCORE: & $.726(3.8)$ & $.693(3.2)$ & $.790(3,0)$ \\
\hline SCORE: & $-.384(2.4)$ & $-.307(1.8)$ & $-.242(0.7)$ \\
\hline RANEBKD & $.095(5.2)$ & $.089 \quad(3.9)$ & .075 (2.4) \\
\hline TPRIZE & $-.012(4.8)$ & $-.012\langle 4.2\rangle$ & $-.013 \quad(2.3)$ \\
\hline$\overline{\mathrm{R}}^{2}$ & .128 & .111 & .176 \\
\hline n & 1,377 & 1.117 & 260 \\
\hline
\end{tabular}

SCORE. : player's first round score in the tournamest.

SCORF2: player's second round score in the tournament.

SCOREs: player's third round score in the cournament.

RANKARD: player's rank after the third round of the tournament.

TPRIZE: total tournament prize money (in thousands).

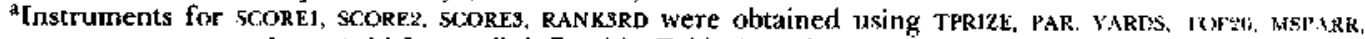
MSAVE, SPARR, SAYE, and MA] (which are all defined in Table 1) and:

ACE: player's age (in years).

MERJT: player's official prize money winnings rank in the year.

SCOREBA: player's scoring average on all third rounds he played on the 1987 tour.

nous, and the estimates in Table 4 are obtained using an instrumental variable method. ${ }^{18}$

Quite striking, as expected, is the evidence in Table 4 that the higher the rank of a player (the poorer his relative position) after the third day of a tournamient, the higher his final round score will be. Moreover, again as expected, the higher the total prize money in a tournament, the lower his score will be. ${ }^{19}$

\footnotetext{
IA The specific variables used to obtain the instruments arc listed itı the notes to ['able 4. Formal specification tests permit us to reject the hypothesis that this set of variables should be treated as exogenous. See Hausman (1978) for these iests.

19 These results are contingent upon sCOREI, SCORE2, SCORE3, and RANKBRD heing treated as endogenous. When thcy are treated as exogenous, the coefficient of IPRIZt remains negative but the coefficient of RAVX $3 R$ D switches sign and beconics negative (significantly so for the all player and nonexempt samples). As noted in footnote 18 . formal specification tests allow us to reject the bypothesis that the above ser of variables should be treated as exogenous.

The results in Table 4 also suggest that a player's sorte on the second round of a tournanient is ans inportant explanatory variable for his final round score. but that the scores on this first and third rounds are less important. It may be that players play "harder" on the sccond round, when they are aware what it will take to make the cut, and on the fouvth round, when the "moncy is at stake." Of course, such
}

Of course, entering a player's rank after three rounds and total tournament prizs money separately only approximates the marginal return to effortconcentration that he faces if he improves his rank by a given number of units. Such a specification also does not take into account how closely his competitors are "bunched" around him. To obtain more precise measures of the relevant marginal returns, we defined six different variables, all of which are illustrated in Figure 2.

Suppose that the curve PP in Figure 2 shows the relationship berween a player's final rank in a tournament and the prize money he will be awarded. Consider an individual who after the third round is at rank $R$. If he remains at that rank. he will be awarded the amount $O A$ at the end of the tournament.

The first three marginal recum variables we compute ignore how tightly competitors are bunched around the player and are based on the return to improving performance, or of having it get worse, by

an explanation suggests that players' helhavior is somewhat inational, as it is their intel sourc alter twe: rounds that determines if they make the cut, and their total score after four that dectrmines thcir prize winnings. 


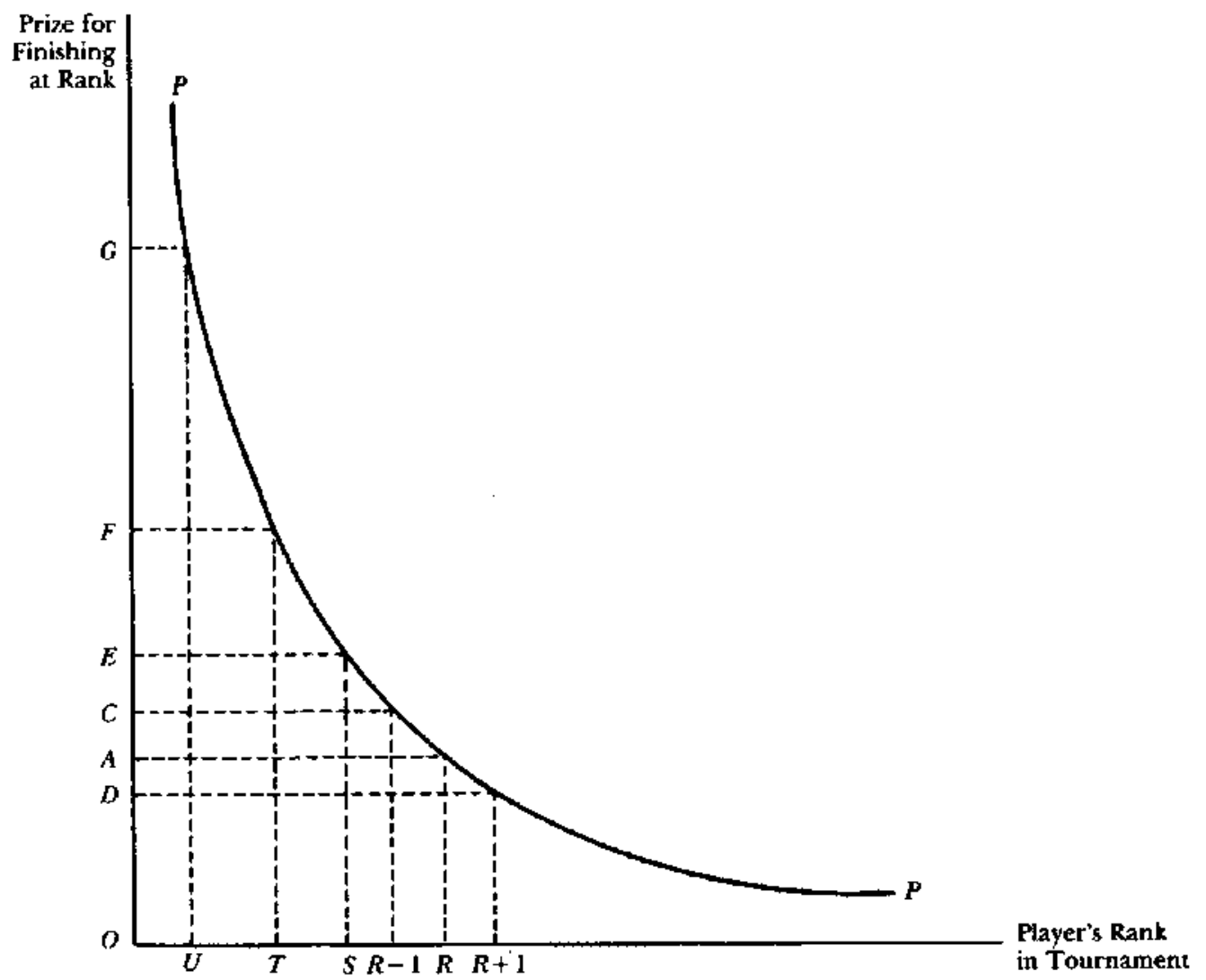

Fignere 2. Alternative Measures of Marginal Return to Effort/Concentration in a Tournament.

one rank. ${ }^{20}$ DPRIZES is the estimated decrease in prize money if the individual's rank at the end of the tournament was one higher (worse) than his current rank. It is given by our estimate of AD. L'PRIZES is the estimated increase in prize money the individual would gain if he improved his rank by one; this is given by $\mathrm{AC}$ in the figure. MIDPRIZ\$ assumes the individual takes into account the cost of losing one

\footnotetext{
20 The marginal returil variables were computed from the following equation, which was estimated using data on all players who finished each of the tournaments in the sample:

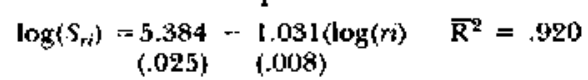

Here, $S_{n}$ is the stare of the total prize money in a tournament that went to the person who finished in the $r$ th place in sournament $i, r$ is that individual's rank in the tournasicent, and standard ertors of the estimates are found beneath the estimated coeffjcients.
}

rank and the benefit from improving one rank. It is defined as the estimated average absolute change in prize moncy if the rank at the end of the tournament is either one lower or one higher than $R$, and it is given in the figure by the average of the lengths of $\mathrm{AC}$ and $\mathrm{AD}$.

Presumably, increased effort/concentration directly affects a player's score, not his rank. The effect of increased concentration on rank then depends on the number of competitors closely bunched around the player. The next three measures take this factor into account; they are the estimated increase in prize money the individual would receive if he improved his scores relative to his competitors by one stroke (LESIPRIZ), two strokes (LES2PRIZ), or three strokes (LES3PRIZ). Assuming that improvements of one, two, and three strokes would cause the individual's rank to improve respectively to $S, T$, and $U$ in the 
Table 5. Coefficients of the Marginal Return to Effort Variables in the Final Round Score Equations for the 1987 PGA Men's European Tour: Data Pooled Across

Tournaments and Playcrs.

(Absolute Value t-Statistics in Parentheses)

\begin{tabular}{|c|c|c|c|}
\hline Specifuation & All Players & Nonexempt Players & Exrmpt Players \\
\hline (1) DPRIZL & $-.570(4.9)$ & $-.936(3.0)$ & $-.148(1.5)$ \\
\hline (2) UPKIZE & $-.794(4.2)$ & $-.895(3.2)$ & $\cdots .159(1.0)$ \\
\hline (3) MUPRIZE & $-.692\langle 4.9\rangle$ & $-.961 \quad(3.3)$ & $-.20 \times(1.5)$ \\
\hline (4) I.ESIPRIZ & $-1.050\langle 3.7\rangle$ & $-1.103(3.4)$ & $-.384(1,3)$ \\
\hline (5) LESQYRIZ & $-.435(4.1)$ & $-.50(1)\langle 3.5\rangle$ & $-.145 \quad(1.6)$ \\
\hline (6) LES3PRIZ & $-.244(3.5)$ & $-.271\langle 3.0\rangle$ & $-.091(1.1)$ \\
\hline
\end{tabular}

DPRIZE: estimated marginal reduction an prize muney (in 000's) if rank at rhc end of the tournament is one higher (worse) than the player i inird roumd rank.

UPR rEt: estimated inarginal increase in rrize money (in 000's) it rank at the end of the rournament is une lower (better) than the player's third round rank.

MIDPRtz.: estimated aterage marginal absolute change in prize money (in 000's) if rank at the che of the toumament is onc Inver or one higher than the individual's third round rank.

I.ESIPRI7: cstimated marginal increase m prize money (in 0100 's) if the individual improved his rank after the

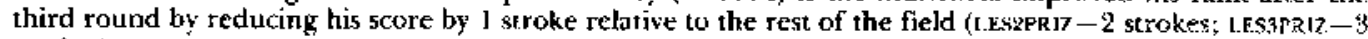
strokes)-

all specifications also include SCORF.I, SCOKE2, and SCORE.3 and use instruments for these variabler and the marginal return to effort variables.

figure, these variables' magnitudes in turn would be given by $\mathrm{AE}, \mathrm{AF}$, and $\mathrm{AG}$.

Each of these six variables was estimated for each individual in each tournament. Each variable in turn was subsrituted for RANK3RD and TPRIZE, and equations similar to those reported in Table 4 were estimated. Because each of these marginal return to effort variables depends on a player's rank after the third round and the latter is endoyenous, instruments were also used for each of these variables.

Estimates of the coefficients of the marginal return to effort variables from these equations are reported in Table 5. 'The pattern of results is remarkably consistent across specifications. The marginal prize variables do affect players' scores on the final round, with larger rraarginal rewards to effort resulting in lower final round scores. ${ }^{21}$ In contrast to the findings in our total score equations (Table 1), the size and significance of these

\footnotetext{
${ }^{21}$ Again, formal specification tests allow us to reject the hyprotieses that the set of earlier round score variables, and each of these variables, should be treated as exogenous. This finding is important. because if one estroueously treats hinse variables as exugenous, the crefficients of all the marginal prize variables switch signs and become positive (significantly so in most cases for the ronextmpt and all player samples).
}

responses appear to be larger for nonexempt players.

One may argue that, in theory, a player's effort on the last round of a tournament also depends on his ability relative to the players who are closcly bunched around him. To see how inclusion of such measures would influence the importance of financial variables, we computed for each playes in each tournament the average ability of players who were within one, two, and three strokes of him, in either direction, at the end of the third round of play in the toumament. 'l'hese variables (one at a time), plus a measure of the player's ability, were added to the specifications that underlie Table 5 , and these extended equations were estimated for the entire sample. Since the average quality of the playcrs around a player after the third round is endogerous, instruments for these average quality variables were also used.

Table 6 summarizes the coelficients of the marginal prize variables that result when ihose changes are made. Column (1) simply repeats the coefficients found in column (1) of Table 5 that came fiorn specifications that did not control for the quality of "nearby" opponents. Colurnis $(2),(3)$, and (4), respectively, present the 
Table 6. Coefficients of the Marginal Return to Effort Variables in the Final Round Score Equations for the 1987 Men's European PGA Tour: Controlling for Quality of Players Nearby After Three Rounds. ${ }^{a}$

(Absolute Value t-Statistics in Parentheses)

\begin{tabular}{|c|c|c|c|c|}
\hline \multirow[b]{2}{*}{$\begin{array}{l}\text { Marginal Return } \\
\text { Variable }\end{array}$} & \multicolumn{4}{|c|}{ Conirol for "Quality" } \\
\hline & $\begin{array}{c}\text { None } \\
\text { (I) }\end{array}$ & $\begin{array}{l}\text { AVESPAR] } \\
\text { (2) }\end{array}$ & $\begin{array}{l}\text { AVESPAR2 } \\
\text { (3) }\end{array}$ & $\begin{array}{l}\text { AVESPAR3 } \\
\text { (4) }\end{array}$ \\
\hline (1) DPRILE & $-.570(4.9)$ & $-.296(2.1)$ & $-.231(1.6)$ & $-.231(1.6)$ \\
\hline (2) UPKIZE & $-.794(4.2)$ & $-.428(2.1)$ & $-.330(1.6)$ & $-.338(1.7)$ \\
\hline (3) MIOPRIZE & $-.692(4.9)$ & $-.371(2.2)$ & $-.290(1.7)$ & $-.292(1.7)$ \\
\hline (4) LIESIPRIZ & $-1.050(3.7)$ & $-.693(2.5)$ & $-.622(2.3)$ & $-.611(2.2)$ \\
\hline (5) lessPRL7. & $-.485(4.1)$ & $-.280(2.5)$ & $-.248(2.2)$ & $-.247(2.3)$ \\
\hline (6) I.FS3PRIZ & $-.244(3.5)$ & $-.152(2.0)$ & $-.126(1.7)$ & $-.130(1.7)$ \\
\hline
\end{tabular}

aperifications are the same as those found in Table 5, with the addition in all but the first columin of measures of the player's ability (SPAR) and the ability of other players close to him after the third round (AVESPARI, AVESPAR2, or AVESPAR3). Since the latter variable is endogenous, instruments for it are also used.

AVESPARI: average number of strokes from par per round during the year of all players within one stroke of the player after third round of the coumament.

AVESPAR2: same as AVESPAR1 but within two strokes.

AVESPAR3: same as AVESPARJ but within three strokes.

coefficients from specifications that control for the quality of other golfers within one, two, and three strokes of the player, respectively, after the third round.

Quite strikingly, although the magnitudes and the statistical significance of the marginal prize variables decline when the controls for average competitor quality are present, larger marginal prizes are still associated with lower final round scores. Furthermore, the coefficients on all of the marginal prize variables remain statistically significantly different from zero.

Table 7 presents descriptive statistics for each of the marginal prize variables. One can use these data and the estimates in Table 6 to obtain estimates of the influence of these variables on players' performance. For example, cetcris paribus, one can estimate for LESIPRIZ and LES2PRIZ how nuch better those players will perform whose marginal prize is one standard deviation above the mean marginal prize in the sample by multiplying the standard deviations in Table 7 by the corresponding regression coefficient in Table $6 .^{22}$ When the quality of players

\footnotetext{
${ }^{22}$ We say [.ESIPRI2 and LES2PRI7. are probably the wo "best" marginal prize variables because they take account of how closely bunched competitors are around the player and because improving onc's performance by three strokes relative to one's
}

nearby after the third round is not included in the equation (Table 6 , column (1)), such calculations suggest that these players would score 3.4 to 4.5 strokes lower on the final round of the tournament. When it is included (Table 6, columns (2)-(3)), these effects fall to roughly 1.9 to 3.0 strokes. Notably, even the latter effects are somewhat larger than the similar effects we found in our earlier paper that used U.S. data.

\section{Concluding Remarks}

This paper and our earlier paper have provided nonexperimental evidence that tournaments do have incentive effects. In our earlier paper, we analyzed data from the 1984 United States Men's PGA Tour and the 1984 United States Senior Men's PGA Tour and found that the level and structure of prize money did influence players' performance. Higher prize levels led, ceteris paribus, to lower scores, although this effect occurred primarily in the later rounds of a tournament, when fatigue had set in and it was

competitors is not an casy task. On average, players in our sample improved their performance by .3 strokes between the third and fourth rounds, and the standard deviation of their change in performance was 3.97 strokes. 
Table 7, Descriptive Statistics-Marginal Prize Variables. ${ }^{\text {a }}$

\begin{tabular}{|c|c|c|c|c|}
\hline Variable & Metn & $\begin{array}{l}\text { Stan- } \\
\text { dard } \\
\text { Devia- } \\
\text { tion }\end{array}$ & $\begin{array}{l}\text { Mini- } \\
\text { mum } \\
\text { Valtue }\end{array}$ & $\begin{array}{l}\text { Maxi- } \\
\text { mum } \\
\text { Value }\end{array}$ \\
\hline DPRIZE & .789 & 3.746 & b & 76.980 \\
\hline UPRIZE & .909 & 4.541 & b & 76.980 \\
\hline MUUPRAZE & .849 & 3.433 & b & 50.395 \\
\hline LFSIPRIZ & 1.058 & 4.327 & b & 76.980 \\
\hline LESQPRIZ & 2.415 & 7.846 & b & $112.16 \theta$ \\
\hline LEssPKIL & 3.895 & 8.791 & b & 126.095 \\
\hline
\end{tabular}

${ }^{2}$ See Table 5 for varjable definitions. All variables are measured in lhousands of pounds.

Less than 0.5 .

more difficult for players to maintain concentration. Given a player's performance on the first three rounds of a tournament, his performance on the last round also appeared, ceteris paribus, to depend on the marginal returns to effort he faced, with players who faced larger marginal returns achieving better scores. The level of prize money in tournaments also influenced who entered the tournaments, with higher prize money attracting better players.

The influence of tournament prizes on performance was observed in the data primarily for exempt players. As discussed in our earlier paper, this result may indicate either that exempt players are more responsive to the reward structure or that a tournament's prize level does not adequately reflect the reward structure that nonexempt players face, since these players must be concerned with how their finish in a tournament will influence their probability of qualifying for exempt status on the next year's tour. Evidence from the U.S. senior tour provided some support for the former hypothesis-that better players are, in fact, more responsive to financial incentives.

Our analysis here, using data from the 1987 Men's European PGA Tour, supports most of the above findings. Higher prize levels appear to lead to lower player scores in the European PGA toumaments, and higher marginal return to effort that players face on the last round of tournaments apparently leads to lower final round scores. The responsiveness of per- formance to prize moncy also appears to be greater on the European than on the U.S. tour. In contrast to the U.S. data, however, the European data yicld only mixed evidence to support the view that exempt players are more responsive to firnancial incentives.

Together, our two papers provide only an exploratory analysis of the incentive effects of tournaments, and there are a number of directions that future research might take. First, replication and extensions using data from other sports in which absolute measures of output are available, the level and structure of prize money differs, and the form of tournaments differs would obvionsiy be desirable. Professional bowling is particularly attractive in this regard, because bowling tournaments have a match play element. ${ }^{23}$

Second, all of our analyses are derived from simple two-person models that yield implications for the calputscores of an individual player. Generalization to n-person tournaments would yield implications about the entire distribution: of scores one might expers to observe, and empirical analyses of the distribution of final scores could then be undertaken.

Third, our analyses assume that the tournament prize structure influences outputscores through its effert on effort concentration levels. Players can also chouse conservative strategies (for example, hitting down the center of the fairway) or risky strategies (for example, trying to cut across a dogleg), and slepending on it player's ability relative to the rest of the field, his rank after each round, of both, different strategies may be pursued. Models that also included the choice of strategies that differ in risk undoubtedly would yicld additional empirical implications.

Fourth, there are normative issues relating to the level and structure of prizes that we actually observe in tournaments. Can

\footnotetext{
2* Research using data froul professional bowling is currently being undertaken by Bugnaniu (forthcoming).
} 
we infer from this structure what the objective functions of the PGA Tour and tournament sponsors actually are? Can we estimate whether the marginal cost to sponsors of higher prize tournaments is less than, equal to, or greater than the marginal benefits they receive? To answer such questions will require going far beyond the scores of players in tournaments and analyzing more generally the operations of the PGA Tour and its sponsors.

Fivally, although studies of sports tournaments are of interest in themselves, there is the broader question of the extent to which tournament theory can help to provide an explanation for the structure of compensa- tion we observe among corporate executives. As is well known, situations in which opportunities exist for one executive to sabotage another's performance are not conducive to tournament-type pay structures. One might, therefore, expect to see tournament-type pay structures used more frequently when rivals can be effectively "separated" (for example, for managers of different branches of a firm) than when they work closely together. ${ }^{24}$ Nevertheless, devising ways to empirically address the relevance of tournament theory should rank high on the research agenda of economists interested in compensation issues.

\footnotetext{
${ }^{24}$ For an extended discussion of this point, see lazear (1989).
}

Appendix

Table A1: 1987 European PGA Tournaments Included in the Sample

\begin{tabular}{|c|c|c|c|}
\hline Tourvamett! & $\begin{array}{c}\text { Total Prize } \\
\text { Money } \\
\text { (in Po1snds) }\end{array}$ & Tournament & $\begin{array}{c}\text { Tolal Prize } \\
\text { Mongy } \\
\text { (in Ponds) }\end{array}$ \\
\hline 1. Morucran Open & 165.398 & 18. Bell's Scottish Open & 200,594 \\
\hline 2. Jersey Open & 98,170 & 14. KL_M Dutch Open & 181,170 \\
\hline 3. Suze Open & 153,105 & 15. Scandinavian Enterprise Open & 193,436 \\
\hline 4. Cepsa Madrid Opcn & 165,000 & 16. PLM Open & 145,998 \\
\hline 5. Laucia Italian Open & 141,697 & 17. Benson \& Hedges International Open & 201,544 \\
\hline fi. Peageat Spanish Open & 175,200 & 18. Lawrence Aatley International & 141,544 \\
\hline 7. Whyle \& Mackay PGA & 220,000 & 19. German Open & 274,555 \\
\hline 8. Iondon Staudards Four Stars & 138,500 & 20. Ebel European Masters Swiss Open & 339,093 \\
\hline 9. Dunhill Rrítish Masters & 200,000 & 21. Panasonic European Open & 221,908 \\
\hline 10. Peugeot French Open & 258,200 & 22. Lancome Ttophy & 300,750 \\
\hline 11. Johnnie Walker Monte Carlo Open & 204,604 & 23. German Masters & 267,684 \\
\hline 12. Carrolls lrish Open & 216,895 & & \\
\hline
\end{tabular}

Distribution of Tournaments by Ptize Money:

$\begin{array}{ll}<100,000 f & 1 \\ 100,000-150,000 \AA & 4 \\ 151,000-200,000 \AA & 7 \\ 200,500-250,000 \AA & 6 \\ 251,000-300,000 \AA & 3 \\ >300,000 x & 2\end{array}$


Table A2: Mexn Percentage and Level of Prize Money Awarded Expost by Ranls in the Tournaments Included in the Sample: Selected Ranks ${ }^{3}$

\begin{tabular}{ccc} 
Final & $\begin{array}{c}\text { Mean Perientage } \\
\text { of Total Prize }\end{array}$ & $\begin{array}{c}\text { Mean Letil of } \\
\text { Pank }\end{array}$ \\
\hline 1 & 16.3 & 34,867 \\
2 & 10.4 & 23.342 \\
8 & 5.8 & 11,918 \\
4 & 4.7 & 10,601 \\
5 & 3.6 & 7,649 \\
19 & 1.18 & 2,378 \\
20 & 1.13 & 1,975 \\
30 & 0.87 & 1,616 \\
40 & 0.61 & 1,479 \\
50 & 0.43 & 1,053 \\
\hline
\end{tabular}

a Authors' calculations from observations included in the sample. As noted in the text, the sample is ronfined to observations on the top 130 money winners during the year. The means for each rank are computed across a different number of observations because two or more golfers may tie for a tank in a giverk touruanent, because no one mav finish in a given rank in a given tournament (e.g., if two golfers tie for tenth. therc is no eleventh-place finisher), or because a golfer who finished in a given rank in a tournament is not in our saiple.

\section{REFERENCES}

Bognanno, Michael. 1088. "Performance lncentives in Tournaments: An Empirical Test." M.S. Thesis, Cornell University, January.

Boguanno, Michael. In progress. "Performance Incentives, Relative Ability Effects, and Tournament Structure," Ph.D. Diss., Coruell University.

Bull, Clive, Andrew Schotter, and Keith Weigett 1987. "Toumaments and Piece Rates: An Experimental Study," Journal of Political Economy, Vol. 95 (February), Pp. 1-33.

Carmichael, H. Lorne. 1983. "The Agent-Agencs Prablem: Payment by Relative Output." Journal of Labor Economics, Vol. 1 (January), pp. 50-65.

Eronomic Report of the President. 1988. Washington, D.C.: GPO.

Ehrenberg. Runald G., and Michael L. Bogmanno. 1988. "Do Tournaments Have Incentive Effecrs?" NBER Research Working Paper No. 2638. June.

Green, Jerry, and Nancy Stokey. 1983. "A Comparison of Toumaments and Contracts." Joumal of Political Economy, Vol, 91 (June), pp. 349-65.

Hausman. J. A. 1978. "Specification Tests in Econometrics." Econometrica, Vol. 46 (November), pp. $1251-71$.

Heckman, James. 1979. "Sample Bias as a Specification Error." Econometrica, Vol. 47 (January), pp. 153-62.

Lazear, Edward. 1989. "Pay Equality and Industrial Policies." Journal of Palitical Economy, Vol. 97 (June), pp. 561-81.
I azear, Edward, and Sherwith Rosirs. "Rank Order Tournaments as an Optjmun labor Comerace." Journal of Political Econemy. Wol. 89 (October). Pp. 841-64.

Malcomson, James M. 1984. "Work Incentives, Hierarchy, and Internal Labor Markc1s," Joumal of Political Esonomy, Vol. 92 (June), Pp. 486-507.

McLaughlin, Kenneth J. 1988. "Aspects of Tournament Models: A Survey." In Ronald G, Ehrenberg, ed., Reseorch in Labor Economics, Vol. 9. Greensich. Conn.: JAI Press, pp. 225-56.

Nalebuft, Barry J+, and Joseph E. Stiglitz, 1984. "Prizes and Incentives: 'Towards a General Theory of Compensation and Competition." Bell Jotumal of Eronomics, Vol. 2 (Springl, pp. 21-43.

O'Keefe, Mary, W. Kip Viscusi. and Richard Zcckhauser. 1984. "Economic Contests: Comparative Reward Schemes." Journal of Labor Eimamics, Vol. 2 (January), pp. 27-56.

O'Reilly, Charles, Brian S. Main, and Gruef S. Crystal. 1988. "CEO Compensation as Tournaments and Social Compatisons: $A$ T'ale of $T$ tras Theories." Administrative Scionie Quarterly, Vol. 33 (June), pp. 257-74.

Pro Gold '8: The Official PGA Eurcpean Tour Gride. 1988. Virginia Waters, Surtey, L'nited Kingdon: PGA Eutopear Tour.

Rosen, Sherwin. "Prizes and Incentives in Flimination Tournamenss." Americon Economia Reriez. Vol. 76 (Septembcr). pp. 701-16. 
Copyright of Industrial \& Labor Relations Review is the property of Cornell University. The copyright in an individual article may be maintained by the author in certain cases. Content may not be copied or emailed to multiple sites or posted to a listserv without the copyright holder's express written permission. However, users may print, download, or email articles for individual use. 